\title{
Destinação de Riqueza aos Acionistas e aos Empregados: Comparação entre Empresas Estatais e Privadas
}

\author{
Betty Lilian Chan \\ Fabiana Lopes da Silva \\ Gilberto de Andrade Martins
}

\begin{abstract}
RESUMO
Diversos estudos empíricos, motivados sobretudo pela suposta ineficiência que se atribui às entidades estatais, foram realizados com o objetivo de investigar o efeito da natureza do controle acionário estatal e privado - sobre o desempenho das firmas. Mas poucos abordaram o efeito desta variável na contribuição da empresa à sociedade em termos de distribuição de riqueza, objeto do presente artigo. Partindo da premissa de que empresas que compõem um mesmo setor oferecem produtos afins e estão expostas a influências externas semelhantes, este estudo busca testar a hipótese de que, no período entre 1998 e 2002, a estrutura de distribuição de renda aos empregados e acionistas das empresas do setor de serviços públicos pode diferir em função da influência do controle acionário, com base nos testes de Mann-Whitney e Kruskall-Wallis. Além disso, buscou-se considerar nessa análise o efeito do porte das empresas, pela técnica multivariada Cluster Analysis. As variáveis analisadas foram extraídas da Demonstração do Valor Adicionado (DVA). Os resultados dos testes efetuados sugerem que as entidades privadas destinaram menor parcela da riqueza gerada aos empregados que as estatais, embora não tenham sido encontrados indícios de que remunerem mais os acionistas, diferindo de alguns estudos assemelhados.
\end{abstract}

Palavras-chave: valor adicionado; performance econômica; controle acionário.

\begin{abstract}
Several empirical studies were made with objective to investigate effects of nature of capital control - public and private - on enterprise performance, motivated mainly for supposed inefficiency of public enterprises. However, few studies investigate effects of this variable for the enterprise contribution to society in the meaning of wealth distribution, which is the objective of this study. Assuming that enterprises that operate in the same sector offer similar products and are exposed to similar influences, this study examines the hypothesis that, during the period from 1998 to 2002, the structure of the wealth distribution to employees and shareholders of the firm which operates in public sector service could differ by the function of capital control influence, tested by MannWhitney and Kruskall-Wallis Test. Besides, we examine effects of the size of firms, orientated by the multivariate technique named Cluster Analysis. The variables analyzed were extracted from Statement of Value Added (SVA). Our results suggest that private enterprises pays a smaller portion of wealth created to employees than public enterprises, despite not found signs that remunerate more shareholders, differing of some similar studies.
\end{abstract}

Key words: value added; economic performance; capital control. 


\section{INTRODUÇÃO}

De acordo com Chan, Corrar e Martins (2003, p. 1), nas últimas décadas, programas de privatização foram implantados em diversos países, tais como: Inglaterra, França, Chile, México, Argentina, Brasil. Um estudo realizado em 1992, pelo Banco Mundial, registrou, até então, mais de 80 países que passaram por essa experiência, o equivalente a cerca de 8.500 empresas estatais.

Segundo Pinheiro e Giambiagi (1992, p. 250), "um dos mais fortes motivos pelos quais um governo pode optar pela transferência de uma empresa estatal para o setor privado é a possibilidade de aumentar a eficiência a nível macro e microeconômico."

Para Werneck (1989, p. 287), "tanto no Brasil como no exterior, ainda há uma convicção muito difundida de que a fonte da ineficiência é simplesmente a propriedade pública".

A suposta ineficiência atribuída às estatais é justificada por não disporem da mesma clareza de objetivos que as empresas privadas, visto que usualmente objetivos sociais são sobrepostos aos objetivos comerciais ou de rentabilidade da empresa. Vale lembrar que, no Brasil, antes da década de 80, para financiar os crescentes déficits em conta corrente do país, as estatais foram obrigadas a contrair empréstimos no exterior. Em 1975, os preços dos seus bens e serviços foram reduzidos em termos reais para controlar a inflação, e, em 1982, para subsidiar a exportação de bens manufaturados. Ou seja, seus objetivos comerciais são, por vezes, sacrificados em prol da manutenção do bem estar social.

Assim, visto que o objetivo principal dessas empresas não é, em princípio, a maximização do lucro ou a minimização do custo, os mecanismos de incentivo e monitoramento do agente também não estariam direcionados para esse fim.

Além disso, as estatais não estariam expostas da mesma maneira que as entidades privadas à disciplina de mercado como instrumento restritivo ao comportamento discricionário do agente; haja vista a diferença de sensibilidade ao risco de falência e de tomada de controle acionário.

Embora essa discussão possa induzir a imaginar-se que as empresas privadas devam apresentar melhor desempenho que as estatais, merece ser lembrado 
que os mercados privados não são, necessariamente, perfeitos. Estudos empíricos, relacionados no Quadro 1 da próxima seção, foram desenvolvidos com intuito de verificar a existência de diferença de desempenho entre esses dois tipos de organizações. A abordagem tradicional privilegia o lucro em detrimento do benefício social proporcionado por essas empresas.

Nesse sentido, o presente artigo tem por objetivo contribuir para os estudos acerca do efeito da propriedade do capital, investigando a sua influência na contribuição da empresa à sociedade em termos da distribuição do valor adicionado aos empregados e acionistas, à luz do modelo de Demonstração do Valor Adicionado (DVA) elaborado pela Fundação Instituto de Pesquisas Contábeis, Atuariais e Financeiras (FIPECAFI) e indicado pela Comissão de Valores Mobiliários (CVM) no Ofício Circular/CVM/SNC/SEP/N ${ }^{\circ}$ 01/00. A análise restringe-se ao setor de serviços públicos durante o período compreendido entre 1998 e 2002.

\section{Desempenho Econômico e Contribuição da Empresa À SOCIEDADE}

Um dos argumentos básicos presente na literatura relativa à suposta ineficiência das empresas estatais, quando comparadas às empresas privadas, reside no efeito da propriedade do capital nas relações entre o agente e o principal, foco da teoria da agência.

Essa teoria, segundo Jensen e Meckling (1976), trata das relações entre os administradores (agentes) e os proprietários ou acionistas (principais), os quais não compartilham, em última análise, dos mesmos objetivos. A questão central é induzir o agente a maximizar o interesse do principal, dada a assimetria informacional entre os mesmos.

Segundo Mello (1992), há várias razões para pressupor que os administradores das empresas estatais não têm um comportamento voltado para a minimização de custos. Uma delas se refere ao objetivo principal dessas entidades não ser, exclusivamente, voltado para a maximização do lucro.

A primazia do enfoque social sobre o comercial é, sobretudo, observada no segmento de serviços públicos. Trata-se de serviço que compete exclusivamente ao Estado, podendo ser delegado à iniciativa privada sob regime de concessão ou permissão. Entre as razões para a centralização de certas atividades, Sundfeld 
(1998, p. 80) destaca: “[...] ordenar o aproveitamento de recursos finitos (como os hidroelétricos), controlar a utilização de materiais perigosos (como os potenciais nucleares), favorecer o rápido desenvolvimento nacional, realizar a justiça social, manter a unidade do país e assim por diante".

São atividades de interesse direto do indivíduo na coletividade. Assim, segundo Slomski (1999, p. 99),

a Teoria do Agenciamento é, talvez, a melhor ferramenta para entender-se que os Agentes devam prestar contas de suas delegações, do início ao fim, pois é certamente na administração pública que deve estar presente a filosofia da accountability. Quando a sociedade elege seus representantes, espera que eles ajam em seu nome de forma correta e que prestem contas de seus atos.

Sendo assim, o Estado exerce dois papéis simultâneos: um de principal em empresas estatais e outro de agente, visto que representa a vontade do povo. Nesse sentido, Pinheiro e Giambiagi (1992, p. 250) dispõem que as estatais:

[...] têm uma face privada e outra pública: de um lado elas têm um objetivo comercial, relacionado à produção e comercialização de um bem ou serviço; de outro, estão os objetivos de política, como o desenvolvimento de setores 'para trás' ou 'para frente' da cadeia produtiva, a integração do território nacional, o atendimento a populações carentes, o nível de emprego, o controle da inflação etc.

Dada a diversidade de objetivos das estatais, os mecanismos de incentivo e monitoramento dos gestores também não estariam, prioritariamente, voltados para a maximização do lucro e/ou minimização do custo.

Por outro lado, quando a propriedade do capital é privada, o corpo gerencial está exposto a outras restrições ao seu comportamento discricionário decorrentes da disciplina de mercado, como, por exemplo, o risco de takeover e o risco de falência. Segundo Passanezi Filho (1998, p. 51),

se as ações de uma determinada firma que não se encontra em seu ponto ótimo forem transacionáveis no mercado de capitais, existirá sempre a possibilidade de um investidor (ou grupo de investidores) fazer uma oferta de compra da totalidade dessas ações e, então realizar uma operação hostil de tomada de controle da companhia. Nesse caso, haveria nova concentração da propriedade e a formação de uma nova estrutura de incentivos que deveria eliminar a subotimalidade da situação anterior. A 
conseqüência dessa eterna ameaça potencial é a impossibilidade de desvios significativos de comportamento do corpo gerencial em relação ao padrão ótimo para companhias cujo controle acionário seja negociável no mercado de capitais.

Como se sabe, não há um mercado de controle acionário para as estatais. Essas organizações têm a possibilidade de recorrer aos cofres públicos e não estão expostas da mesma forma que as empresas privadas ao risco de falência.

Esse raciocínio é, freqüentemente, utilizado como base argumentativa a favor da privatização. Segundo Pinheiro (1996, p. 357), "é a busca de maior eficiência que efetivamente justifica, do ponto de vista teórico, a implementação de programas de desestatização". Pois, além do benefício relativo ao suposto aumento de eficiência da economia, o crescimento dos lucros e rendas proporciona, conseqüentemente, elevação das receitas fiscais.

Entretanto não se pode afirmar que empresas privadas são sempre mais eficientes que empresas estatais, porquanto, conforme Passanezi Filho (1998, p. 64), "os mercados privados não são perfeitos, podendo engendrar sérios desvios em relação ao comportamento ótimo". Os referidos desvios poderão ocorrer em virtude, por exemplo, de assimetria de informações, de dispersão da propriedade acionária, de predomínio de acionistas passivos, dentre outras causas.

Diversos estudos empíricos foram desenvolvidos na tentativa de testar a superioridade, em termos de performance econômica e financeira, das empresas privadas em relação às estatais. No Quadro 1, é apresentada uma síntese das principais conclusões obtidas em alguns desses estudos. 


\section{Quadro 1: Resultados Empíricos sobre a Eficiência Relativa de Empresas Estatais e Privadas}

\begin{tabular}{|c|c|c|c|}
\hline Setor & $\begin{array}{l}\text { Empresa estatal mais } \\
\text { eficiente }\end{array}$ & $\begin{array}{l}\text { Resultado ambíguo ou sem } \\
\text { diferenças de eficiência }\end{array}$ & $\begin{array}{c}\text { Empresa privada mais } \\
\text { eficiente }\end{array}$ \\
\hline Eletricidade & $\begin{array}{c}\text { Meyer (1975) } \\
\text { Neuberg (1977) } \\
\text { Pescatrice e Trapani (1980) }\end{array}$ & $\begin{array}{c}\text { Mann (1970) } \\
\text { Junker (1975) } \\
\text { Spann (1977) } \\
\text { Färe et al. (1985) } \\
\text { Atkinson e Halvorsen (1986) }\end{array}$ & $\begin{array}{l}\text { Shepherd (1966) } \\
\text { Moore (1970) } \\
\text { Peltzman (1971) } \\
\text { Tilton (1973) } \\
\text { De Alessi (1974) }\end{array}$ \\
\hline Coleta de lixo & Pier et al. (1974) & $\begin{array}{l}\text { Hirsch (1965) } \\
\text { Kemper e Quigley (1976) } \\
\text { Collins e Downes (1977) }\end{array}$ & $\begin{array}{c}\text { Kitchen (1976) } \\
\text { Savas (1977) } \\
\text { Pommerehne e Frey (1977) } \\
\text { Stevens (1978) } \\
\text { Edwards e Stevens (1978) }\end{array}$ \\
\hline Água & $\begin{array}{l}\text { Mann e Mikesell (1971) } \\
\text { Bruggink (1982) }\end{array}$ & Feigenbum e Teeples (1983) & $\begin{array}{c}\text { Hausman (1976) } \\
\text { Morgan (1977) } \\
\text { Crain e Zardkoohi (1978, } \\
\text { 1980) }\end{array}$ \\
\hline $\begin{array}{l}\text { Serviços de } \\
\text { saúde }\end{array}$ & & Becker e Sloan (1985) & $\begin{array}{c}\text { Clarkson (1972) } \\
\text { Rushing (1974) } \\
\text { Lindsay (196) } \\
\text { Frech (1976) } \\
\text { Bays (1979) } \\
\text { Frech (1980) } \\
\text { Bishop (1980) } \\
\text { Frech e Ginsburg (1981) } \\
\text { Finsinger (1982) } \\
\text { Wilson e Jadlow (1982) } \\
\text { Schlesinger e Dorwart } \\
\text { (1984) }\end{array}$ \\
\hline $\begin{array}{l}\text { Companhias } \\
\text { aéreas }\end{array}$ & & $\begin{array}{c}\text { Forsyth e Hocking (1980) } \\
\text { Morrison (1981) } \\
\text { Jordan (1982) }\end{array}$ & $\begin{array}{l}\text { Davies (1971) } \\
\text { Davies (1977) }\end{array}$ \\
\hline Ferrovias & & $\begin{array}{c}\text { Caves e Christensen (1980) } \\
\text { Caves et al. (1982) }\end{array}$ & \\
\hline $\begin{array}{l}\text { Instituições } \\
\text { Financeiras }\end{array}$ & & Lewin (1982) & Davies (1981) \\
\hline $\begin{array}{l}\text { Seviços contra } \\
\text { incêndios }\end{array}$ & & & Ahlbrecht (1973) \\
\hline $\begin{array}{l}\text { Transporte não } \\
\text { ferroviário }\end{array}$ & & & $\begin{array}{c}\text { Pashigian (1976) } \\
\text { Palmer et al. (1983) } \\
\text { McGuire e Van Cott (1984) }\end{array}$ \\
\hline
\end{tabular}

Fonte: Pinheiro, 1996, p. 377.

Como se pode observar, as evidências empíricas a esse respeito ainda são pouco conclusivas. Mais recentemente, outros estudos foram realizados, como o 
de: Boardman e Vining (1989), Megginson, Nash e Randenborgh (1994), Pinheiro (1996), D’Souza e Megginson (1999), Chan et al. (2003), dentre outros.

Boardman e Vining (1989) utilizaram regressões para comparar o desempenho relativo das empresas privadas e estatais. Para tanto, estabeleceram uma variável dependente de performance (ex.: retorno sobre o patrimônio, vendas por empregado etc.) e algumas variáveis explicativas (ex.: tamanho, nacionalidade, segmento de atividade etc.), juntamente com variáveis dummies, a fim de captar o efeito da propriedade do capital sobre o desempenho. Concluíram que as empresas públicas e de economia mista apresentaram desempenho estatisticamente inferior às privadas.

Megginson et al. (1994), Pinheiro (1996), D’Souza e Megginson (1999) utilizaram o Wilcoxon Signed Rank Test e o Teste dos Sinais para analisar os desempenhos das empresas antes e depois de serem alienadas, encontrando resultados estatisticamente significantes que sugerem que, após a privatização, o desempenho melhorou.

Chan et al. (2003) realizaram uma avaliação da privatização brasileira durante o período compreendido entre 1995 e 2002, à luz de indicadores operacionais e financeiros extraídos de demonstrações contábeis. Compararam não apenas o comportamento das empresas antes e depois de serem privatizadas, mas também com a média, no mesmo período, das empresas do mesmo setor que permaneceram como estatais, com o intuito de tentar isolar o efeito do capital da influência de fatores macroeconômicos sobre a performance das empresas. Os resultados dos testes estatísticos aplicados sugeriram que as empresas analisadas, após a alienação do controle acionário, reduziram o número de empregados, aumentaram a lucratividade, a eficiência operacional, o volume de vendas e mudaram o perfil de endividamento. Entretanto, com exceção do aumento da lucratividade, um comportamento similar também foi percebido nas empresas que continuaram como estatais, o que levou a supor que os demais resultados foram decorrentes de fatores macroeconômicos que afetaram todo o setor, não cabendo atribuir ao efeito da mudança de controle acionário.

A abordagem tradicional dos estudos nessa área está voltada para a análise do desempenho econômico e financeiro, privilegiando-se indicadores relacionados ao lucro líquido, cujos principais interessados são os sócios, acionistas ou proprietários. Entretanto, a questão da privatização ou concessão de serviços públicos também pode ser analisada sob a ótica da contribuição da empresa à comunidade.

As empresas não atuam isoladamente, mas interagem com o ambiente em que se inserem. Cada vez mais o aspecto de responsabilidade social é discutido e 
valorizado. Começa a ser observado que as empresas não exercem apenas o papel de agente econômico, mas também de agente social, uma vez que influenciam diretamente a qualidade de vida dos trabalhadores e da comunidade.

Além disso, segundo Yoshioca (1998, p. 8):

A economia estuda a alocação de recursos escassos para produtos ilimitados, ou seja, como obter o máximo de satisfação para os indivíduos a partir de um dado estoque de recursos. Para satisfazer às suas necessidades, o homem envolve-se em um ato de produção. A produção é a atividade social que visa adaptar a natureza para a criação de bens e serviços que permitam a satisfação de necessidades humanas. Desse modo, a produção é a principal atividade econômica a ser medida, uma vez que refletirá a capacidade de satisfação das necessidades dos membros da sociedade.

Nesse sentido, a Contabilidade dispõe da DVA que busca evidenciar a relação empresa-sociedade, por meio da divulgação de quanto de valor esta adiciona aos insumos que adquire e como o distribui entre os seguintes agentes econômicos: empregados, governo, credores ou financiadores externos e acionistas.

Para Santos (1999, p. 98):

A Demonstração do Valor Adicionado - DVA, componente importantíssimo do Balanço Social, deve ser entendida como a forma mais competente criada pela Contabilidade para auxiliar na medição e demonstração da capacidade de geração, bem como de distribuição, da riqueza de uma entidade.

O termo riqueza aqui empregado se aproxima do conceito de Produto Interno Bruto (PIB), com algumas diferenças, principalmente, de ordem temporal.

Conforme Tinoco (1996, p. 34):

A origem deste demonstrativo foi o documento publicado em 1975, pelo 'Accounting Standards Steering Committee', intitulado 'The Corporate Report', que ilustrou a vontade de reunir informação econômica e social, num relatório suscetível de informar a uma só vez aos investidores e aos assalariados, isto é, permitir a divulgação da informação àqueles que têm razoavelmente direito a uma informação: significativa, compreensível, completa, objetiva e comparável.

Com base nesse demonstrativo, é possível inferir, por exemplo, o benefício proporcionado pela empresa à sociedade em termos de pagamento de impostos, taxas e contribuições ao governo, o nível de participação da mão-de-obra na geração da riqueza e o nível de remuneração do capital próprio e de terceiros. 


\section{Base de Dados e Metodologia}

A tipologia de pesquisa adotada se baseia predominantemente em uma abordagem empírico-analítica.

Partindo da premissa de que empresas que compõem um mesmo setor oferecem produtos afins e estão expostas a influências externas semelhantes, este estudo busca testar a hipótese de que, no período entre 1998 e 2002, o percentual de riqueza destinado aos empregados e acionistas, referente às empresas do setor de serviços públicos, pode diferir em função da influência do controle acionário e do porte dessas organizações. Trata-se de uma análise comparativa entre a estrutura de distribuição de renda das empresas estatais e privadas, observandose a possível similaridade em termos de porte das organizações, orientada pela técnica multivariada Cluster Analysis.

As variáveis estudadas são os percentuais de riqueza gerada que são destinados aos empregados e acionistas, calculados a partir da DVA.

Segundo Boycko, Shleifer e Vishny (1996, p. 309), a causa mais comum observada relativa à suposta ineficiência das empresas estatais é o excesso de mão-de-obra. Dessa forma, é de se esperar que o percentual de riqueza gerada pela empresa e distribuída aos empregados, em média, nas estatais seja superior às empresas privadas.

Uma decorrência direta da presunção de maior eficiência das empresas privadas é que estas, ao vender mais e reduzir o excesso de mão-de-obra, tornam-se mais lucrativas e pagam mais impostos.

Logo, a expectativa é que o percentual médio de riqueza gerada e destinada aos acionistas seja superior à média das empresas estatais.

Sendo assim, o presente artigo visa testar a existência de indícios, com base em ferramentas estatísticas, em nível de significância de $1 \%$, que, durante o período compreendido entre 1998 e 2002, no setor de serviços públicos, o percentual médio da riqueza gerada e distribuída (a) para os empregados é superior em empresas estatais; (b) para os acionistas é superior em empresas privadas; e (c) não houve alteração significativa no percentual de riqueza destinado a estes dois agentes econômicos, tanto nas empresas privadas como nas estatais, ao longo do período analisado.

As informações foram obtidas a partir do banco de dados da FIPECAFI, o qual contempla cerca de 4.000 empresas e é utilizado para a edição da Revista Exame 
- Melhores e Maiores. Foram selecionadas todas as empresas do setor de serviços públicos que disponibilizaram a DVA e que dispunham de informações relativas ao número de empregados, total do ativo, vendas e patrimônio líquido. Esses dados foram ajustados pelos efeitos da inflação e atualizados para 31.12.2002. A composição da amostra é apresentada na Tabela 1.

Tabela 1: Composição da Amostra

\begin{tabular}{|c|c|c|c|c|c|c|}
\hline $\mathbf{N}^{\mathbf{0}}$ de Empresas & $\mathbf{1 9 9 8}$ & $\mathbf{1 9 9 9}$ & $\mathbf{2 0 0 0}$ & $\mathbf{2 0 0 1}$ & $\mathbf{2 0 0 2}$ & Total \\
\hline Privadas & 33 & 43 & 48 & 55 & 53 & 232 \\
\hline Estatais & 33 & 38 & 44 & 40 & 41 & 196 \\
\hline Total da Amostra & $\mathbf{6 6}$ & $\mathbf{8 1}$ & $\mathbf{9 2}$ & $\mathbf{9 5}$ & $\mathbf{9 4}$ & $\mathbf{4 2 8}$ \\
\hline
\end{tabular}

Os testes podem ser divididos em duas etapas. A primeira consiste na comparação dos percentuais médios das variáveis a serem analisadas, segregadas em dois grupos de empresas (estatais e privadas), aplicando-se o teste de MannWhitney em cada ano. Trata-se de um teste não paramétrico destinado a verificar se duas amostras independentes provêm de populações com médias iguais, em nível de significância pré-estabelecido. Esse teste consiste na atribuição de postos às observações, como se estas fizessem parte de uma única amostra. Se a hipótese nula for verdadeira, então os postos baixos, médios e altos estariam distribuídos equilibradamente entre as duas amostras.

Além disso, para cada grupo de empresas, comparou-se a média anual de cada variável ao longo dos cinco anos, a fim de testar se permaneceu sem mudança significativa durante o período analisado. Para tanto, foi utilizado outro teste não paramétrico conhecido como Kruskal-Wallis. Martins (2001, p. 280) esclarece que se trata de um teste "[...] extremamente útil para decidir se $K$ amostras $(K>$ 2) independentes provêm de populações com médias iguais".

A segunda etapa visa avaliar tais hipóteses não apenas em função do setor de serviços públicos, mas também em relação ao porte das empresas. Para tanto, foi utilizada a ferramenta estatística de Clusters Analysis (Análise de Conglomerados). Trata-se de uma técnica multivariada que permite segregar elementos ou variáveis em grupos homogêneos internamente, heterogêneos entre si e mutuamente excludentes, a partir de determinados parâmetros conforme uma medida de distância ou similaridade. Os parâmetros selecionados para a caracterização do porte foram estes: total do ativo, total do patrimônio líquido, vendas e número de empregados. Para viabilizar a utilização dessa técnica, esses valores foram padronizados pelo método do $Z$ scores, que, conforme Hair, Tatham, Anderson e Black (1998, p. 489), é o mais comum. 
Foi adotado o enfoque conhecido como hierarchical clustering, cujo processo de agregação trata cada entidade, a princípio, isoladamente como um cluster e, a partir de uma medida de semelhança, é iniciado o agrupamento.

Dentre as diversas medidas de distâncias existentes, selecionou-se a Squared Euclidean Distance, por ser recomendável para a aplicação do método de aglomeração denominada de Ward's Method.

Após segregar a amostra em conglomerados, repetiu-se os testes de MannWhitney e Kruskal-Wallis para aqueles que continham mais de 20 elementos.

\section{AnÁlise dos Resultados}

\section{Evolução da Estrutura de Distribuição de Riqueza aos Empregados e Acionistas}

Os resultados da aplicação do teste de Mann-Whitney para investigar o comportamento do percentual médio de riqueza distribuída a cada agente econômico, conforme a natureza do controle acionário, são sintetizados na Tabela 2. Se $p$-value for superior ao nível de significância pré-estabelecido, no caso $1 \%$, o resultado do teste sugere que a hipótese nula de igualdade de médias não pode ser rejeitada e, se for inferior, não deve ser aceita.

Tabela 2: Síntese dos Resultados do Teste de Mann-Whitney

\begin{tabular}{|c|c|c|c|c|c|c|c|}
\hline \multirow{2}{*}{ Empregados } & \multirow{2}{*}{$\begin{array}{l}\mathrm{H} 0: \quad \mu_{\text {privada }}=\mu_{\text {estatal }} \\
\mathrm{H1}: \quad \mu_{\text {privada }}\left\langle\mu_{\text {estatal }}\right.\end{array}$} & \multicolumn{2}{|c|}{ Empresas } & \multirow{2}{*}{ Acionistas } & \multirow{2}{*}{$\begin{array}{ll}\mathrm{H} 0: & \mu_{\text {privada }}=\mu_{\text {estatal }} \\
& \left.\mu_{\text {privada }}\right\rangle \mu_{\text {estatal }}\end{array}$} & \multicolumn{2}{|c|}{ Empresas } \\
\hline & & Privadas & Estatais & & & Privadas & Estatais \\
\hline \multirow{3}{*}{1998} & $\mathrm{n}$ & 33 & 33 & \multirow{3}{*}{1998} & $\mathrm{n}$ & 33 & 33 \\
\hline & Média dos postos & 24,21 & 42,79 & & Média dos postos & 36,27 & 30,73 \\
\hline & P-Value (uni-caudal) & \multicolumn{2}{|c|}{0,000} & & P-Value (uni-caudal) & \multicolumn{2}{|c|}{0,121} \\
\hline \multirow{3}{*}{1999} & $\mathrm{n}$ & 43 & 38 & \multirow{3}{*}{1999} & $\mathrm{n}$ & 43 & 38 \\
\hline & Média dos postos & 33,14 & 49,89 & & Média dos postos & 38,88 & 43,39 \\
\hline & P-Value (uni-caudal) & \multicolumn{2}{|c|}{0,001} & & P-Value (uni-caudal) & \multicolumn{2}{|c|}{0,195} \\
\hline \multirow{3}{*}{2000} & $\mathrm{n}$ & 48 & 44 & \multirow{3}{*}{2000} & $\mathrm{n}$ & 48 & 44 \\
\hline & Média dos postos & 33,44 & 60,75 & & Média dos postos & 48,35 & 44,48 \\
\hline & P-Value (uni-caudal) & \multicolumn{2}{|c|}{0,000} & & P-Value (uni-caudal) & \multicolumn{2}{|c|}{0,244} \\
\hline \multirow{3}{*}{2001} & $\mathrm{n}$ & 55 & 40 & \multirow{3}{*}{2001} & $\mathrm{n}$ & 55 & 40 \\
\hline & Média dos postos & 37,25 & 62,78 & & Média dos postos & 49,60 & 45,80 \\
\hline & P-Value (uni-caudal) & \multicolumn{2}{|c|}{0,000} & & P-Value (uni-caudal) & \multicolumn{2}{|c|}{0,254} \\
\hline \multirow{3}{*}{2002} & $\mathrm{n}$ & 53 & 41 & \multirow{3}{*}{2002} & $\mathrm{n}$ & 53 & 41 \\
\hline & Média dos postos & 35,43 & 63,10 & & Média dos postos & 46,25 & 49,12 \\
\hline & P-Value (uni-caudal) & & & & P-Value (uni-caudal) & \multicolumn{2}{|c|}{0,306} \\
\hline
\end{tabular}


Como pode ser observado na Tabela 2, durante o período analisado, o $p$-value referente ao percentual do valor adicionado distribuído aos empregados é menor que o nível de significância de $1 \%$, o que leva à rejeição da hipótese de igualdade de médias entre empresas estatais e privadas, sugerindo a existência de indícios de que, em média, a participação dos empregados na distribuição de riqueza é maior nas estatais. Esse resultado, analisado isoladamente, poderia induzir a imaginar que de fato as estatais gastam mais com mão-de-obra, o que fortaleceria a idéia da sua suposta ineficiência. Entretanto, contrariando as expectativas, ao analisar os resultados pertinentes ao grau de remuneração dos acionistas, verificase que não foram constatadas diferenças significativas entre esses dois grupos de empresas, no período analisado.

Assim sendo, não seria apropriado considerar que os resultados apontam a ineficiência das estatais, mas indicam, tendo-se em vista que na composição da distribuição do valor adicionado há ainda dois outros agentes econômicos - governo e credores, que, provavelmente, as empresas estatais remuneram, em termos percentuais, mais os empregados em detrimento ao governo ou credores que as empresas privadas.

Para Mello (1992, p. III. 1), haveria 3 razões principais para se supor que os gestores das empresas estatais não estejam voltados prioritariamente para a minimização de custos ou maximização de lucro:

. “[...] a empresa estatal não tem o lucro como objetivo e, quando deficitária, é protegida da falência pelo socorro dos cofres públicos.

. [...] costuma-se atribuir às empresas estatais um número muito grande de objetivos que freqüentemente são conflitantes. À minimização de custos costuma ser dado um grau baixo de prioridade. Além disso, os políticos comumente usam as empresas estatais para alcançar objetivos não comerciais de motivação política, com prejuízos para o desempenho da empresa.

. [...] a remuneração dos gerentes das empresas estatais não está relacionada à geração de lucros e, portanto, à minimização de custos."

Portanto, esperava-se que as empresas privadas apresentassem melhores performances econômica e financeira que as estatais, mas os resultados empíricos dessa pesquisa não fortalecem essa suposição.

A Tabela 3, a seguir, mostra os resultados do Teste de Kruskal-Wallis, que foi utilizado para verificar se, durante o período analisado, houve alteração na composição da distribuição de riqueza aos dois agentes econômicos em exame: empregados e acionistas. 
Tabela 3: Síntese dos Resultados do Teste de Kruskal-Wallis

\begin{tabular}{|c|c|c|c|c|c|c|c|}
\hline $\begin{array}{l}\text { H0: } \mu_{1998}=\mu_{1999}=\mu_{2000}=\mu_{2001}=\mu_{2002} \\
\text { H1: Há ao menos uma diferença nas médias anuais }\end{array}$ & \multicolumn{3}{|c|}{ Empresas Privadas } & \multicolumn{3}{c|}{ Empresas Estatais } \\
\hline Variáveis & Ano & $\mathbf{n}$ & $\begin{array}{c}\text { Média dos } \\
\text { Postos }\end{array}$ & P-Value & n & $\begin{array}{c}\text { Média dos } \\
\text { Postos }\end{array}$ & P-Value \\
\hline & 1998 & 33 & 137,27 & & 33 & 108,88 & \\
Percentual de Valor Adicionado Distribuído para & 1999 & 43 & 130,00 & & 38 & 99,41 & \\
Empregados & 2000 & 48 & 123,05 & 0,031 & 44 & 108,55 & 0,260 \\
& 2001 & 55 & 104,21 & & 40 & 85,44 & \\
& 2002 & 53 & 99,43 & & 41 & 91,27 & \\
Percentual de Valor Adicionado Distribuído para & 1998 & 33 & 148,48 & & 33 & 109,00 & \\
Acionistas & 1999 & 43 & 91,93 & & 38 & 92,84 & \\
& 2000 & 48 & 119,69 & 0,000 & 44 & 95,59 & 0,356 \\
& 2001 & 55 & 136,31 & & 40 & 109,06 & \\
\hline
\end{tabular}

Com base nos resultados do teste de Kruskal-Wallis, sintetizados acima, verificase, ao longo do período analisado, que o percentual da riqueza gerada destinada aos empregados se manteve, em média, sem alteração significativa, tanto nas empresas estatais como nas empresas privadas, em nível de significância préestabelecido.

Quanto ao grau de remuneração do capital próprio, verifica-se a existência de indícios de que nas empresas privadas houve alguma alteração no período, se considerado o nível de significância de 1\%. Já nas empresas estatais, não foram constatados indícios que levem a supor alterações significativas no grau de remuneração do capital próprio.

Contrapondo esses resultados, um estudo efetuado por Pinheiro (1996) concluiu que com a privatização ocorreu uma melhora significativa, em termos estatísticos, do desempenho das empresas. Dentre evidências encontradas por Pinheiro (1996, p. 371) observou-se redução significativa no numero de empregados após a privatização. Entretanto, esse estudo não analisou se tal fato foi um fenômeno observável em todo o setor.

Para tentar isolar o efeito do capital dos demais fatores macroeconômicos Chan et al. (2003), já citados anteriormente, compararam não apenas o comportamento das empresas antes e depois de serem privatizadas, mas também com a média, no mesmo período, das empresas do mesmo setor que permaneceram como estatais. Os autores concluíram que as empresas analisadas, após a privatização reduziram o número de empregados e aumentaram a lucratividade. Entretanto, a redução do número de empregados também foi observada nas empresas do mesmo setor que permaneceram como estatais.

Silva, Santos e Chan (2003) efetuaram um estudo sobre os efeitos da privatização na distribuição do valor adicionado de 8 companhias que passaram pela desestatização e confrontaram os resultados com mais 20 companhias que 
permaneceram estatais no período analisado. Foi verificado que as empresas que compõem o grupo de controle, ou seja, que permaneceram como estatais, tiveram, no período compreendido entre 1996 e 2002, redução na participação de gastos com pessoal e encargos inferior a 10 pontos percentuais, enquanto em algumas empresas que foram privatizadas a redução foi de 20 ou mais pontos percentuais. Além disso, ao analisar a distribuição de riqueza aos acionistas das empresas privatizadas e as que permaneceram estatais concluíram que o comportamento de ambos os grupos foi similar, em consonância com os resultados encontrados nessa pesquisa.

A pesquisa de Megginson et al. (1994, p. 403), por sua vez, verificou uma melhora na performance das companhias privatizadas, sem sacrifício do nível de emprego. Vale destacar que esse estudo envolveu 61 companhias de 18 países e 32 setores da economia.

Conforme pode observar-se no Quadro 1, mostrado anteriormente, diversos estudos dedicados aos mesmos setores produziram resultados diferentes, ora sugerindo que empresas privadas são mais eficientes, ora não constatando diferenças significativas. Entretanto, poucos estudos analisaram o efeito do controle acionário sobre a ótica da destinação de riqueza aos agentes econômicos, acionistas e empregados, foco desta pesquisa. Ou seja, a maioria dos estudos que tratam do efeito do capital estatal e privado privilegia o lucro em detrimento ao valor adicionado gerado pela entidade, o que dificulta a comparabilidade dos resultados.

\section{Evolução da Estrutura de Distribuição de Riqueza aos Empregados e Acionistas Conforme o Porte das Empresas}

Pela técnica de Cluster Analysis, segregou-se a amostra em grupos considerados, ao menos em parte, homogêneos internamente quanto ao porte das empresas. O número de clusters foi determinado privilegiando a formação de ao menos dois conglomerados com no mínimo 20 elementos cada.

A distribuição de freqüência por ano e por cluster é apresentada na Tabela 4 a seguir: 
Tabela 4: Distribuição de Freqüência entre Clusters

\begin{tabular}{|c|c|c|c|c|c|}
\hline & $\mathbf{1 9 9 8}$ & $\mathbf{1 9 9 9}$ & $\mathbf{2 0 0 0}$ & $\mathbf{2 0 0 1}$ & $\mathbf{2 0 0 2}$ \\
\hline Total de Clusters & $\mathbf{7}$ & $\mathbf{6}$ & $\mathbf{6}$ & $\mathbf{5}$ & $\mathbf{6}$ \\
\hline Distribuição de freqüiência & & & & & \\
\hline Cluster 1 & 32 & 44 & 53 & 61 & 49 \\
\hline Cluster 2 & 21 & 25 & 27 & 25 & 36 \\
\hline Cluster 3 & 2 & 4 & 4 & 4 & 3 \\
\hline Cluster 4 & 3 & 4 & 4 & 4 & 4 \\
\hline Cluster 5 & 4 & 3 & 3 & 1 & 1 \\
\hline Cluster 6 & 3 & 1 & 1 & & 1 \\
\hline Cluster 7 & 1 & & & & \\
\hline Total & $\mathbf{6 6}$ & $\mathbf{8 1}$ & $\mathbf{9 2}$ & $\mathbf{9 5}$ & $\mathbf{9 4}$ \\
\hline
\end{tabular}

Para os conglomerados formados com mais de 20 elementos ('cluster 1' e 'cluster 2'), foram aplicados os testes de Mann-Whitney e Kruskal-Wallis.

A síntese dos resultados é apresentada nas Tabelas 5, 6, 7 e 8, na seqüência.

Tabela 5: Síntese dos Resultados do Teste de Mann-Whitney para Médias de Valor Adicionado Distribuído para Empregados por Cluster

\begin{tabular}{|c|c|c|c|c|c|c|c|}
\hline \multirow{2}{*}{ Cluster 1} & \multirow{2}{*}{$\begin{array}{ll}\text { H0: } & \mu_{\text {privada }}=\mu_{\text {estatal }} \\
\text { H1: } & \mu_{\text {privada }}\left\langle\mu_{\text {estatal }}\right.\end{array}$} & \multicolumn{2}{|c|}{ Empresas } & \multirow{2}{*}{ Cluster 2} & \multirow{2}{*}{$\begin{array}{l}\mathrm{H} 0: \quad \mu_{\text {privada }}=\mu_{\text {estatal }} \\
\mathrm{H} 1: \quad \mu_{\text {privada }}\left\langle\mu_{\text {estatal }}\right.\end{array}$} & \multicolumn{2}{|c|}{ Empresas } \\
\hline & & Privadas & Estatais & & & Privadas & Estatais \\
\hline \multirow{3}{*}{1998} & $\mathrm{n}$ & 21 & 11 & \multirow{3}{*}{1998} & $\mathrm{n}$ & 9 & 12 \\
\hline & Média dos postos & 12,24 & 24,64 & & Média dos postos & 6,22 & 14,58 \\
\hline & P-Value (uni-caudal) & \multicolumn{2}{|c|}{0,000} & & P-Value (uni-caudal) & \multicolumn{2}{|c|}{ 0,001 } \\
\hline \multirow{3}{*}{1999} & $\mathrm{n}$ & 27 & 17 & \multirow{3}{*}{1999} & $\mathrm{n}$ & 13 & 12 \\
\hline & Média dos postos & 19,26 & 27,65 & & Média dos postos & 8,92 & 17,42 \\
\hline & P-Value (uni-caudal) & \multicolumn{2}{|c|}{0,018} & & P-Value (uni-caudal) & \multicolumn{2}{|c|}{0,002} \\
\hline \multirow{3}{*}{2000} & n & 31 & 22 & \multirow{3}{*}{2000} & $\mathrm{n}$ & 13 & 14 \\
\hline & Média dos postos & 20,29 & 36,45 & & Média dos postos & 8,69 & 18,93 \\
\hline & P-Value (uni-caudal) & \multicolumn{2}{|c|}{0,000} & & P-Value (uni-caudal) & \multicolumn{2}{|c|}{0,001} \\
\hline \multirow{3}{*}{2001} & $\mathrm{n}$ & 38 & 23 & \multirow{3}{*}{2001} & $\mathrm{n}$ & 15 & 10 \\
\hline & Média dos postos & 24,18 & 42,26 & & Média dos postos & 9,07 & 18,90 \\
\hline & P-Value (uni-caudal) & \multicolumn{2}{|c|}{0,000} & & P-Value (uni-caudal) & \multicolumn{2}{|c|}{0,001} \\
\hline \multirow{3}{*}{2002} & $\mathrm{n}$ & 29 & 20 & \multirow{3}{*}{2002} & $\mathrm{n}$ & 21 & 15 \\
\hline & Média dos postos & 19,55 & 32,90 & & Média dos postos & 13,24 & 25,87 \\
\hline & P-Value (uni-caudal) & & & & P-Value (uni-caudal) & \multicolumn{2}{|c|}{0,000} \\
\hline
\end{tabular}

Ao nível de significância de 1\%, os resultados da aplicação do teste de MannWhitney nos dois clusters sugerem que empresas estatais distribuíram maior percentual da sua riqueza gerada aos empregados que as empresas privadas, ao longo do período analisado, salvo no ano de 1999 no 'cluster 1 '. Tal resultado foi consistente com o obtido anteriormente, exibido na Tabela 2. 
Tabela 6: Síntese dos Resultados do Teste de Mann-Whitney para Médias de Valor Adicionado Distribuído para Acionistas por Cluster

\begin{tabular}{|c|c|c|c|c|c|c|c|}
\hline \multirow{2}{*}{ Cluster 1} & \multirow{2}{*}{$\begin{array}{l}\mathrm{H} 0: \quad \mu_{\text {privada }}=\mu_{\text {estatal }} \\
\left.\mathrm{H1}: \mu_{\text {privada }}\right\rangle \mu_{\text {estatal }}\end{array}$} & \multicolumn{2}{|c|}{ Empresas } & \multirow{2}{*}{ Cluster 2} & \multirow{2}{*}{$\begin{array}{l}\mathrm{H} 0: \quad \mu_{\text {privada }}=\mu_{\text {estatal }} \\
\mathrm{H1}: \quad \mu_{\text {privada }}>\mu_{\text {estatal }}\end{array}$} & \multicolumn{2}{|c|}{ Empresas } \\
\hline & & Privadas & Estatais & & & Privadas & Estatais \\
\hline \multirow{3}{*}{1998} & $\mathrm{n}$ & 21 & 11 & \multirow{3}{*}{1998} & $\mathrm{n}$ & 9 & 12 \\
\hline & Média dos postos & 18,52 & 12,64 & & Média dos postos & 13,56 & 9,08 \\
\hline & P-Value (uni-caudal) & \multicolumn{2}{|c|}{0,046} & & P-Value (uni-caudal) & \multicolumn{2}{|c|}{0,051} \\
\hline \multirow{3}{*}{1999} & $\mathrm{n}$ & 27 & 17 & \multirow{3}{*}{1999} & $\mathrm{n}$ & 13 & 12 \\
\hline & Média dos postos & 20,85 & 25,12 & & Média dos postos & 13,23 & 12,75 \\
\hline & P-Value (uni-caudal) & \multicolumn{2}{|c|}{0,142} & & P-Value (uni-caudal) & \multicolumn{2}{|c|}{0,435} \\
\hline \multirow{3}{*}{2000} & $\mathrm{n}$ & 31 & 22 & \multirow{3}{*}{2000} & $\mathrm{n}$ & 13 & 14 \\
\hline & Média dos postos & 28,45 & 24,95 & & Média dos postos & 14,85 & 13,21 \\
\hline & P-Value (uni-caudal) & \multicolumn{2}{|c|}{0,209} & & P-Value (uni-caudal) & \multicolumn{2}{|c|}{0,297} \\
\hline \multirow{3}{*}{2001} & $\mathrm{n}$ & 38 & 23 & \multirow{3}{*}{2001} & $\mathrm{n}$ & 15 & 10 \\
\hline & Média dos postos & 32,87 & 27,91 & & Média dos postos & 13,40 & 12,40 \\
\hline & P-Value (uni-caudal) & \multicolumn{2}{|c|}{0,146} & & P-Value (uni-caudal) & \multicolumn{2}{|c|}{0,370} \\
\hline \multirow{3}{*}{2002} & $\mathrm{n}$ & 29 & 20 & \multirow{3}{*}{2002} & $\mathrm{n}$ & 21 & 15 \\
\hline & Média dos postos & 23,34 & 27,40 & & Média dos postos & 19,57 & 17,00 \\
\hline & P-Value (uni-caudal) & $\mathbf{0 , 1}$ & & & P-Value (uni-caudal) & \multicolumn{2}{|c|}{0,235} \\
\hline
\end{tabular}

Os resultados relativos à remuneração do capital próprio, considerando o porte, foram consistentes com os obtidos anteriormente, conforme Tabela 2. Pela Tabela 6 , observa-se que não foram constatadas evidências que levem à rejeição da hipótese nula de igualdade de médias, contrariando-se as expectativas iniciais.

A fim de verificar se houve alteração significativa na estrutura de distribuição de renda aos empregados e acionistas, ao longo do período analisado, observando o porte das empresas, efetuou-se o teste de Kruskal-Wallis, tanto para o 'Cluster 1 ' como para o 'Cluster 2', cujos resultados são sintetizados na Tabela 7 e 8.

\section{Tabela 7: Síntese dos Resultados do Teste de Kruskal-Wallis Aplicados ao 'Cluster 1'}

\begin{tabular}{|c|c|c|c|c|c|c|c|}
\hline $\begin{array}{l}\text { H0: } \mu_{1998}=\mu_{1999}=\mu_{2000}=\mu_{2001}=\mu_{2002} \\
\text { H1: Há ao menos uma diferenças nas médias anuais }\end{array}$ & \multicolumn{3}{|c|}{ Empresas Privadas } & \multicolumn{3}{c|}{ Empresas Estatais } \\
\hline Variáveis & Ano & $\mathbf{n}$ & $\begin{array}{c}\text { Média dos } \\
\text { Postos }\end{array}$ & P-Value & n & $\begin{array}{c}\text { Média dos } \\
\text { Postos }\end{array}$ & P-Value \\
\hline & 1998 & 21 & 84,90 & & 11 & 58,64 & \\
Percentual de Valor Adicionado Distribuído para & 1999 & 27 & 77,83 & & 17 & 48,18 & \\
Empregados & 2000 & 31 & 76,84 & 0,384 & 22 & 52,05 & 0,286 \\
& 2001 & 38 & 69,47 & & 23 & 40,39 & \\
\hline Percentual de Valor Adicionado Distribuído para & 2002 & 29 & 62,91 & & 20 & 41,65 & \\
Acionistas & 1998 & 21 & 90,52 & & 11 & 42,55 & \\
& 2099 & 27 & 59,15 & & 17 & 48,71 & \\
& 2000 & 31 & 72,76 & 0,007 & 22 & 41,86 & 0,569 \\
\hline
\end{tabular}


Tabela 8: Síntese dos Resultados do Teste de Kruskal-Wallis Aplicados ao 'Cluster 2'

\begin{tabular}{|c|c|c|c|c|c|c|c|}
\hline $\begin{array}{l}\text { H0: } \mu_{1998}=\mu_{1999}=\mu_{2000}=\mu_{2001}=\mu_{2002} \\
\text { H1: Há ao menos uma diferença nas médias anuais }\end{array}$ & \multicolumn{3}{|c|}{ Empresas Privadas } & \multicolumn{3}{c|}{ Empresas Estatais } \\
\hline Variáveis & Ano & n & $\begin{array}{c}\text { Média dos } \\
\text { Postos }\end{array}$ & P-Value & n & $\begin{array}{c}\text { Média dos } \\
\text { Postos }\end{array}$ & P-Value \\
\hline & 1998 & 9 & 42,72 & & 12 & 37,67 & \\
Percentual de Valor Adicionado Distribuído para & 1999 & 13 & 46,46 & & 12 & 35,33 & \\
Empregados & 2000 & 13 & 39,77 & 0,051 & 14 & 35,71 & 0,208 \\
& 2001 & 15 & 25,53 & & 10 & 21,80 & \\
& 2002 & 21 & 31,79 & & 15 & 28,13 & \\
Percentual de Valor Adicionado Distribuído para & 1998 & 9 & 50,78 & & 12 & 32,00 & \\
Acionistas & 1999 & 13 & 24,46 & & 12 & 29,21 & \\
& 2000 & 13 & 39,38 & 0,022 & 14 & 35,36 & 0,687 \\
& 2001 & 15 & 41,47 & & 10 & 36,95 & \\
\hline
\end{tabular}

Conforme pode constatar-se pelas Tabelas 7 e 8 , tanto no 'cluster 1 ' quanto no 'cluster 2', em nível de significância de 1\%, nas empresas estatais e nas privadas, os resultados sugerem que o perfil da composição da distribuição do valor adicionado, em média, não se alterou ao longo do período compreendido entre 1998 e 2002. A única exceção observada foi no 'cluster 1', referente ao grau de remuneração do capital próprio em entidades privadas.

\section{Considerações Finais}

A discussão da influência do controle acionário sobre a gestão empresarial é carregada de teorias hipotético-dedutivas de difícil generalização, visto que existem inúmeras variantes em relação às situações propostas teoricamente, conforme se menciona na segunda seção dessa pesquisa.

Diversos foram os estudos acerca da análise do efeito da natureza do controle acionário sobre o desempenho das firmas. Entretanto, pouco se refletiu sobre o seu impacto no contexto social, foco do presente artigo.

A principal dificuldade encontrada nos estudos empíricos deste gênero é isolar o efeito do capital, dada a diversidade de variáveis a que uma organização está sujeita.

Não se trata aqui de uma tentativa de avaliação geral da destinação do valor adicionado gerado aos empregados e acionistas, em entidades estatais e privadas, dado o caráter restrito da amostra, adstrita ao período compreendido entre 1998 e 2002 e às empresas do setor de serviços públicos que dispunham de informações acerca da DVA.

A análise desenvolvida neste artigo sugere que a distribuição de renda, em 
termos percentuais relativos à riqueza total criada, nas empresas estatais do setor analisado não se alterou significativamente entre 1998 e 2002.

As empresas privadas, por sua vez, também não apresentaram mudanças significativas, ao longo do período analisado, no percentual médio do valor adicionado distribuído para empregados. Entretanto, dependendo da observância ou não do porte dessas entidades, o grau de remuneração dos acionistas pode ou não ter indícios de alterações significativas.

Embora os resultados dos testes efetuados, em geral, levem a supor que as estatais destinam maior parcela da sua riqueza gerada aos empregados que as empresas privadas, não se pode deduzir que seja um indício de ineficiência das estatais, porquanto, não se pode analisar esse resultado isoladamente, visto que a composição da distribuição do valor adicionado contempla, além dos empregados, outros agentes econômicos: governo, credores e acionistas.

Em todos os testes efetuados para a variável referente ao grau de remuneração dos acionistas, os resultados sugerem não haver diferenças significativas entre esses dois grupos de empresas.

Portanto, analisando os resultados em conjunto, supõe-se que embora as estatais remunerem mais os empregados, em termos percentuais da riqueza gerada, tal fato não pode ser atribuído à sua suposta ineficiência, visto que não foram constatadas diferenças significativas no grau de remuneração do capital próprio. Assim, pressupõe-se que as estatais devem destinar menor parcela da sua riqueza aos credores ou ao governo que as entidades privadas.

\section{Artigo recebido em 04.11.2004. Aprovado em 13.04.2005.}

\section{REFERÊNCIAS BibliográfICAS}

Banco Mundial (1992, July). Policy views from the country economics department. Recuperado em 29 dezembro, 2002 de http:// www.worldbank.org/html/prddr/ outreach/or3.htm

Boardman, A. E., \&

Vining, A. R. (1989).

Ownership and performance in competitive environments: a comparison of the performance of private, mixed, and state-owned enterprises. Journal of Law \& Economics, 32(1), 1-33.

Boycko, M.,

Shleifer, A., \&

Vishny, R. W. (1996).

A theory of privatization. The

Economic Journal, 106(435), 309-319. 
Chan, B. L.,

Corrar, L. J., \&

Martins, G. A. de (2003).

Avaliação da privatização brasileira sob a ótica do desempenho operacional e financeiro. Anais do Encontro Nacional dos Programas de Pós-Graduação em Administração, Atibaia, SP, Brasil, 27.

D’Souza, J., \&

Megginson, W. L. (1999).

The financial and operating performance of privatized firms during the 1990s. The Journal of Finance, 54(4), 1397-1438.

Hair, J. F.,

Tatham, R. L.,

Anderson, R. E., \&

Black, W. (1998).

Multivariate data analysis (5th ed., p. 730). New Jersey: Prentice Hall.

Jensen, M. C., \&

Meckling, W. H. (1976).

Theory of the firm: managerial behavior, agency costs and ownership structure. Journal of Financial Economics, 3(4), 305-360. Recuperado em 10 março, 2003, de http://papers.ssrn.com/sol3/ paper.taf?ABSTRACT_ID=94043

Martins, G. A. (2001).

Estatística geral e aplicada (p. 417).

São Paulo: Atlas.

Megginson, W. L.,

Nash, R. C., \&

Randenborgh, M. V. (1994).

The financial and operating performance of newly privatized firms: an international empirical analysis. The Journal of Finance, 49(2), 403-451.
Mello, M. F. de (1992).

A privatização no Brasil: análise dos seus fundamentos e experiências internacionais. Tese de Doutorado, Faculdade de Economia, Administração e Contabilidade, Universidade de São Paulo, SP, Brasil.

Passanezi Filho, R. (1998).

Privatização e reforma institucional da infra-estrutura no Brasil - em busca de ganhos fiscais e de eficiência econômica. Tese de doutoramento não-publicada, Faculdade de Economia, Administração e Contabilidade, Universidade de São Paulo, SP, Brasil.

Pinheiro, A. C. (1996).

Impactos microeconômicos da privatização no Brasil. Pesquisa e Planejamento Econômico, 26(3), 357397.

Pinheiro, A. C., \&

Giambiagi, F. (1992).

As empresas estatais e o programa de privatização do governo Collor. Pesquisa e Planejamento Econômico, 22(2), 241-288.

Santos, A. dos (1999).

Demonstração contábil do valor adicionado - DVA - um instrumento para medição da geração $e$ distribuição de riqueza das empresas. Tese de livre docência, Faculdade de Economia, Administração e Contabilidade da Universidade de São Paulo, SP, Brasil. 
Silva, F. L. da,

Santos, A. dos, \&

Chan, B. L. (2003).

Uma contribuição ao estudo dos impactos da privatização à luz da demonstração do valor adicionado. Anais do Congresso USP de Controladoria e Contabilidade, São Paulo, SP, Brasil, 3.

Slomski, V. (1999).

Teoria do agenciamento no Estado: uma evidenciação da distribuição de renda econômica produzida pelas entidades públicas de administração direta. Tese de Doutorado, Faculdade de Economia, Administração e Contabilidade da Universidade de São Paulo, SP, Brasil.

Sundfeld, C. A. (1998).

Fundamentos de direito público (3a ed., p. 176). São Paulo: Malheiros Editores.
Tinoco, J. E. P. (1996).

Contribuição ao estudo da contabilidade estratégica de recursos humanos. Tese de Doutorado, Faculdade de Economia, Administração e Contabilidade da Universidade de São Paulo, SP, Brasil.

Werneck, R. L. F. (1989).

Aspectos macroeconômicos da privatização no Brasil. Pesquisa e Planejamento Econômico, 19(2), 277307.

Yoshioca, R. (1998, fevereiro).

Valor adicionado - alguns conceitos econômicos que ajudam a entender a demonstração contábil. Temática Contábil e Balanços [Boletim Contábil, ano 32, (8) pp. 1-5]. São Paulo, SP: IOB. 